\title{
Uncovering the signaling pathways involved in CNS disorders
}

\section{Tsong-Hai Lee \\ Pei-Shan Liu \\ Ming-Ming Tsai \\ Jiun-Liang Chen \\ Su-Jane Wang \\ Hsi-Lung Hsieh}

\section{Video Byte}

Keywords: bradykinin, matrix metalloproteinase-9, COX-2/PGE2 autocrine, STAT3, brain astrocytes, neuroinflammation, Cell Communication and Signaling

Posted Date: October 16th, 2021

DOI: https://doi.org/10.21203/rs.3.rs-978559/v1

License: (c) (i) This work is licensed under a Creative Commons Attribution 4.0 International License. Read Full License 


\section{Abstract}

Central nervous system (CNS) disorders affect millions of people worldwide. Two key inflammatory pathways in the CNS are coming under the spotlight. In the first, expression of the protein matrix metalloproteinase 9 (MMP9) occurs through a pathway mediated by bradykinin (BK), and in the second, the protein cyclooxygenase-2 (COX-2) mediates increased prostaglandin E2 (PGE2) production. However, how these two pathways interact in brain astrocytes remains unclear. A recent study sought to uncover the relationship between these pathways using biochemical assays of rat brain astrocytes. The researchers found that BK activated COX-2 in pro-inflammatory astrocytes, leading to PGE2 production and release from astrocytes, which induced MMP9 expression and activated signaling cascades, ultimately promoting astrocyte migration. Although further study in vivo is needed, these results provide new insights into the inflammatory mechanisms of BK and COX-2/PGE2 action, which may be recognized as therapeutic targets in brain inflammatory diseases. 